\title{
Floral homeotic mutations produced by transposon-mutagenesis in Antirrhinum majus
}

\author{
Rosemary Carpenter ${ }^{1}$ and Enrico S. Coen \\ John Innes Institute, AFRC Institute of Plant Science Research, Norwich NR4 7UH, UK
}

To isolate and study genes controlling floral development, we have carried out a large-scale transposonmutagenesis experiment in Antirrhinum majus. Ten independent floral homeotic mutations were obtained that could be divided into three classes, depending on whether they affect (1) the identity of organs within the same whorl; (2) the identity and sometimes also the number of whorls; and (3) the fate of the axillary meristem that normally gives rise to the flower. The classes of floral phenotypes suggest a model for the genetic control of primordium fate in which class 2 genes are proposed to act in overlapping pairs of adjacent whorls so that their combinations at different positions along the radius of the flower can specify the fate and number of whorls. These could interact with class 1 genes, which vary in their action along the vertical axis of the flower to generate bilateral symmetry. Both of these classes may be ultimately regulated by class 3 genes required for flower initiation. The similarity between some of the homeotic phenotypes with those of other species suggests that the mechanisms controlling whorl identity and number have been highly conserved in plant evolution. Many of the mutations obtained show somatic and germinal instability characteristic of transposon insertions, allowing the cell-autonomy of floral homeotic genes to be tested for the first time. In addition, we show that the deficiens (def) gene (class 2) acts throughout organ development, but its action may be different at various developmental stages, accounting for the intermediate phenotypes conferred by certain def alleles. Expression of def early in development is not necessary for its later expression, indicating that other genes act throughout the development of specific organs to maintain def expression. Direct evidence that the mutations obtained were caused by transposons came from molecular analysis of leaf or flower pigmentation mutants, indicating that isolation of the homeotic genes should now be possible.

[Key Words: Antirrhinum majus; homeotic genes; def; transposons]

Received February 27, 1990; revised version accepted June 4, 1990.

The flower is one of the most intensively studied organ systems in plants. Many mutations affecting the developmental fate of its organ primordia have been documented in diverse species, although there have been few attempts to relate these in a systematic way to the mechanism of floral development (Masters 1869; Worsdell 1915; Meyer 1966; Meyerowitz et al. 1989). These mutations are homeotic in the classical sense as they result in "the assumption by one member of a meristic series, of the form or characters proper to other members of the series" (Bateson 1894). Indeed, when Bateson coined the term, homeosis, he referred specifically to the early work on plant teratologies by von Goethe (1790) and Masters (1869). In comparison with well-studied cases of homeosis in some other systems, most notably Drosophila, homeosis in plants shows some distinguishing features. One important difference is that plant organs are often produced sequentially so that distinct

\footnotetext{
${ }^{1}$ Corresponding author.
}

organ types may arise at different times in development. Homeotic mutations can therefore change both the times and locations at which particular organs develop. Consequently, as well as being homeotic, the mutations can be considered to be heterochronic as they may result in precocious or related development similar to certain mutations in Caenorhabditis (Ambros and Horvitz 1984). In contrast, different segments in Drosophila arise almost synchronously so that homeosis is generally considered separately from heterochrony.

We used transposon-mutagenesis to generate floral homeotic mutations with a view to studying and isolating the genes involved. One advantage of this approach is that transposon integration can be used to tag genes, and transposon excision can be used to prove that the correct gene has been isolated (Shepherd 1987; Wienand and Saedler 1987). In addition, imprecise excision can generate alleles with altered gene expression, thus providing useful material for studying gene function and regulation (Sommer et al. 1988; Almeida et al. 1989). Finally, somatic excision can indicate if the af- 
fected gene acts cell autonomously and can also be exploited to "rescue" sterile or lethal mutations.

Antirrhinum majus provides an ideal experimental system for this approach. Three different transposons (Tam1, Tam2, and Tam3), representing two distinct transposon families, have been isolated and characterized from this species (Bonas et al. 1984; Sommer et al. 1985; Upadhaya et al. 1985; Krebbers et al. 1987), and transposon-tagging has been used successfully for gene isolation (Martin et al. 1985). Several genes encoding flower pigment biosynthetic enzymes have been isolated and provide good markers for monitoring transposition and for trapping new transposons (Coen et al. 1986; Sommer and Saedler 1986). Antirrhinum has large flowers that are easy to score phenotypically and are convenient to emasculate and cross. Consequently, it has a good genetic map with many well-characterized mutations affecting flower development (Stubbe et al. 1966). Finally, sterile mutants can be readily propagated vegetatively through cuttings.

To isolate and subsequently analyze genes by transposon-tagging, a known active transposon needs to be inserted into a gene of interest. One approach to this problem would be to set up a large-scale direct self-pollination program by using lines carrying active transposons. This approach should allow the isolation of homozygous recessive mutations in known isogenic backgrounds in the $\mathrm{M}_{2}$ generation. It should also allow transposons to be trapped in genes that have already been cloned, thus allowing isolation and characterization of any new transposons active in the stock. Any novel transposons trapped by this method could then be used as molecular tags for gene isolation and may also lead to a greater understanding of transposon behavior and evolution. Here, we describe floral homeotic mutations obtained from such an experiment; direct evidence that these and other mutations were caused by transposon insertion will be presented elsewhere (E. Coen, S. Doyle, and R. Carpenter, in press; D. Luo, E. Coen, S. Doyle, and R. Carpenter, unpubl.).

Flowers of Antirrhinum majus are borne in a spiral up the stem in a racemose inflorescence. Each flower grows in the axil of a bract and is zygomorphic: It can be divided into two halves by a single longitudinal plane. In transverse plane, the flower may be considered as comprising four concentric rings or whorls, each containing several organ members (Fig. 1). The members will be referred to as upper or lower, depending on their positions relative to the bract, which is considered to be the lowest organ. In addition, members lying in the plane of symmetry will be referred to as middle members. The first or outermost whorl comprises five sepals, the lowest two being alternate to the bract. The corolla occupies the second whorl and consists of five petals; these are united for part of their length to form a tube that terminates in five lobes. The two upper lobes have a shape distinct from the lower three. Five stamen primordia are initiated alternately with the petals and constitute the third whorl. The uppermost middle stamen primoridum fails to develop fully and yields an aborted

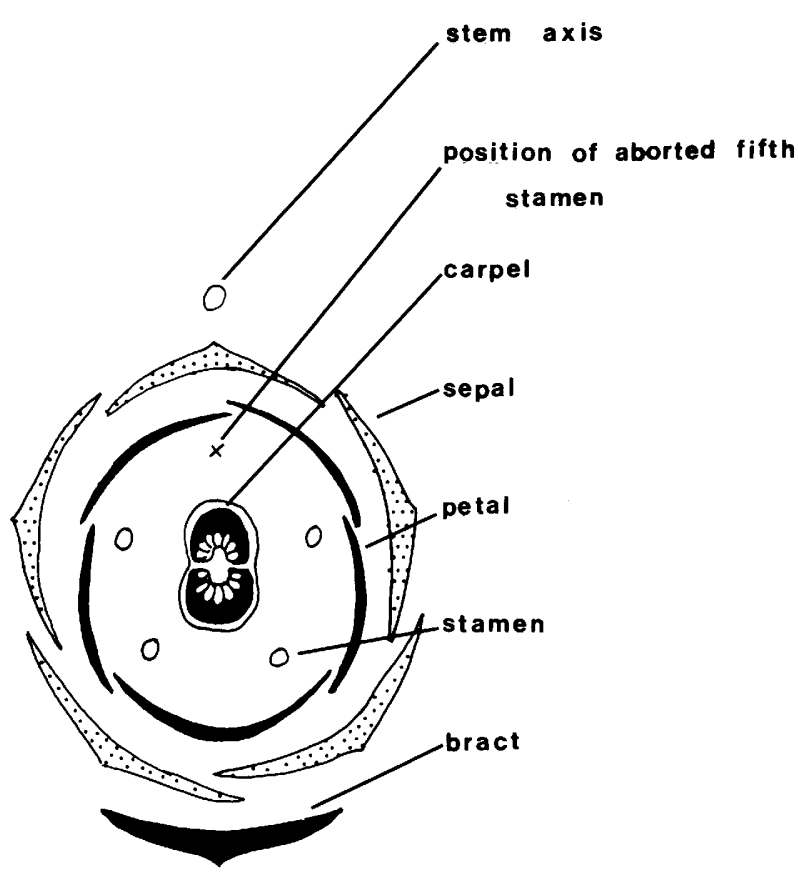

Figure 1. Floral diagram of a wild-type Antirrhinum flower.

or rudimentary structure. Consequently, the adult flower has only four stamens, the upper two being shorter than the lower pair. The central, fourth whorl is occupied by two united carpels forming a gynoecium with a bilocular ovary. For brevity, the identity of whorls will be indicated in sequence starting from the first whorl; thus, in the wild-type flower, the order is sepal (whorl 1), petal (whorl 2), stamen (whorl 3), and carpel (whorl 4). The different whorls appear sequentially, with the outer whorl (1) developing first and the central whorl (4) last (Awasthi et al. 1984).

\section{Results}

\section{Transposon mutagenesis strategy}

Several plants from lines carrying highly active transposons were grown at $15^{\circ} \mathrm{C}$, the temperature at which greatest transposition of the Tam elements occurs (Harrison and Fincham 1964; Harrison and Carpenter 1973; Carpenter et al. 1987). These plants were self-pollinated and gave rise to $13,000 M_{1}$ progeny. Taking a few selfed seeds from each of these plants gave an $M_{2}$ generation of 40,000 plants (see Materials and methods for details). Several flower homeotic and pigment mutations were obtained and selected for detailed analysis. Analysis of the pigment mutations will be presented in a separate paper (D. Luo, E. Coen, S. Doyle, and R. Carpenter, unpubl.). Here, we describe the genetic analysis of the homeotic mutations (Table 1).

\section{Homeotic mutations}

cycloidea-608 and cycloidea-609 Two independent mutations were obtained that gave flowers with a more radially symmetrical appearance than wild type. Several 
Table 1. Mutations of Antirrhinum majus obtained by transposon tagging

\begin{tabular}{lclr}
\hline Mutant & Stock number & Description & Progenitor \\
\hline Wild-type morphology & 98,75 & sepal, petal, stamen, carpel & \\
Homeotic mutant & 608 & semi-peloric flowers & 75 \\
cycloidea & 609 & trumpet-shaped flowers & 75 \\
deficiens & 621 & sepal, sepal, carpel & 522 \\
sepaloidea & 620 & sepal, sepal, carpel & T144 \\
& 619 & sepal, split petals, stamen, carpel & 605 \\
ovulata & 627 & carpel, stamen, stamen, carpel & 98 \\
pleniflora & 624 & sepal, petal, petal, variable, petal, etc. & \\
& 625 & & \\
floricaula & 626 & & \\
\hline
\end{tabular}

The identity of the whorls is indicated in sequence starting from the first or outermost whorl.

different cycloidea $(c y c)$ mutations affecting radial symmetry have been described previously (Darwin 1868; Stubbe 1966), and for ease of comparison, the most extreme of these, cyc-25, will be considered first. This allele gives a peloric phenotype: Flowers are radially symmetrical, and all members of whorls two and three resemble the lowest members of the corresponding whorl in wild-type flowers. For example, the uppermost middle stamen is not aborted but grows as a typical lower stamen. The number of members in the three outer whorls of the flower varies between 5 and 6 .

One of the new mutations obtained gave semipeloric flowers with six sepals and petals and five or six stamens. The three lower petal lobes resembled the middle lowest lobe of wild type. Two of the upper lobes were hybrid in form, the lower half of the lobe resembling a lower wild-type lobe and the upper half resembling an upper wild-type lobe. The uppermost lobe was small and tended to fold forward, giving the flower a more rounded shape than normal. Crossing the mutant to lines carrying various cyc alleles gave mutant $\mathrm{F}_{1}$ phenotypes (Fig. 2), whereas backcrossing to the wildtype progenitor gave wild-type flowers. Thus, the mutation was a recessive $c y c$ allele, subsequently referred to homozygotes

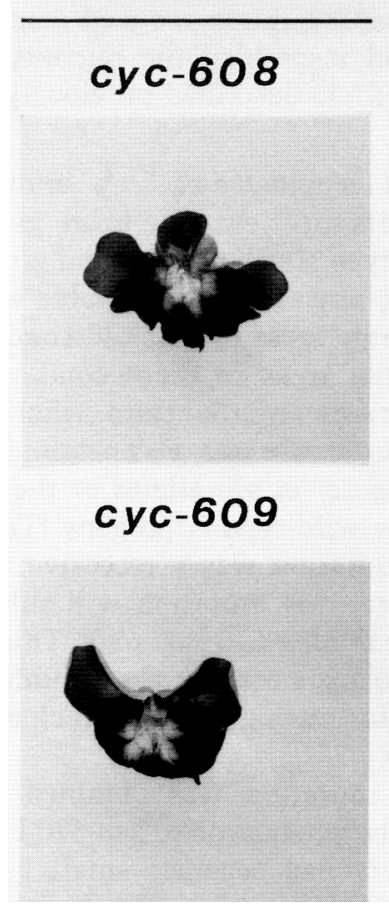

heterozygotes

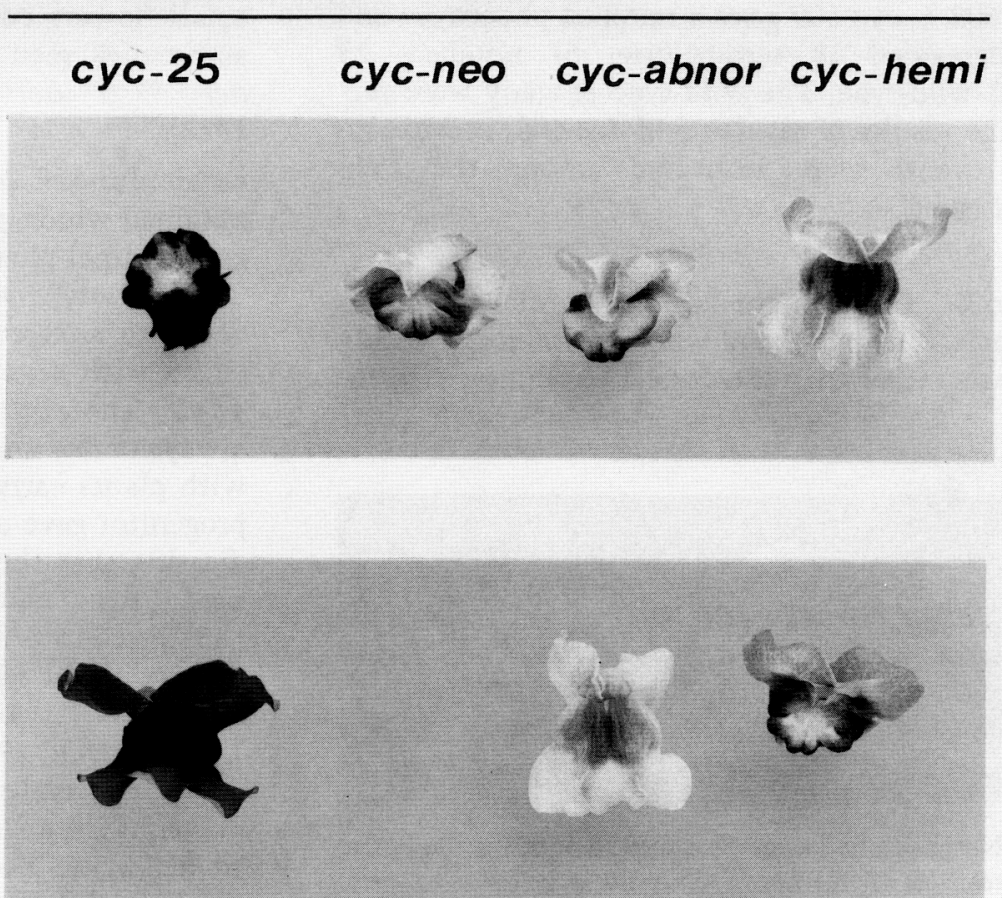

Figure 2. The two complementation groups of $c y c$ mutations. (Left) Flowers of the homozygous cyc-608 and cyc-609 lines; $($ right $) \mathbf{F}_{1}$ heterozygotes obtained when homozygous cyc-608 and cyc-609 were crossed with the known homozygous cyc mutations, cyc-25, $c y c^{n e o}, c y c^{a b n o r}$, and $c y c^{h e m i}$, described previously. 
as cycloidea-608 (cyc-608). Interestingly, the cross with cycloidea ${ }^{\text {hemiradialis }}\left(\right.$ cychemi) gave an almost wild-type $F_{1}$ phenotype, with flowers showing a small notch at the joint between the upper and lower lobes, resulting in a partially open corolla (Fig. 3). This phenotype is less severe than that of either parent, indicating that $c y c-608$ and $c y c^{\text {hemi }}$ show partial complementation. A similar phenomenon has also been observed for the cross of $c y$. cloidea $a^{\text {neohemiradialis }}\left(\right.$ cyc $\left.^{\text {neo }}\right)$ with cycloidea ${ }^{\text {radialis }}\left(\right.$ cyc $\left.^{\text {rad }}\right)$ (von Kuckuck 1936). From 1487 progeny of cyc-608, $0.34 \%$ had a revertant wild-type phenotype, and two showed a fully peloric phenotype similar to $c y c-25$, indicating germinal instability.

A second, independent mutation gave a more symmetrical, trumpet-like flower than wild type. The two upper lobes retained much of their wild-type appearance, but the three lower lobes resembled the middle lobe of wild type, turning over and down toward the corolla tube, to give an overall flattened appearance to the flowers. Crossing the mutant to lines carrying various cyc alleles gave mutant $F_{1}$ phenotypes, whereas backcrossing to wild type gave wild-type flowers. Thus, the mutation was a recessive $c y c$ allele, subsequently referred to as cycloidea-609 (cyc-609). The $F_{1}$ phenotype of the cross with $c y c^{\text {hemi }}$ gave a trumpet phenotype, but all other crosses gave the almost wild-type notched phenotype described above (Fig. 3). This is the converse of the results obtained with $c y c-608$ and indicates that there are two groups of $c y c$ alleles: (1) cyc-608, cyc-25, cycloidea abnormis $\left(c y c^{a b n o r}\right), c y c^{\text {neo }}$, and (2) cyc-609, cychemi. Crosses between alleles from the two groups showed partial complementation with the notched phenotype described above. In agreement with this, the $F_{1}$ of the cross cyc- $608 \times$ cyc- 609 gave a notched phenotype and the $\mathrm{F}_{2}$ segregated 28 semipeloric; 61 notched; 25 trumpet; 2 wild-type. The wild-type progeny were presumably the results of reversion of cyc-608, because no reversion events were recovered among the 1578 progeny of $c y c-609$.

deficiens-621 This mutant had the normal outer ring of five sepals, but the second whorl contained five individual sepals rather than the corolla of wild type. In the

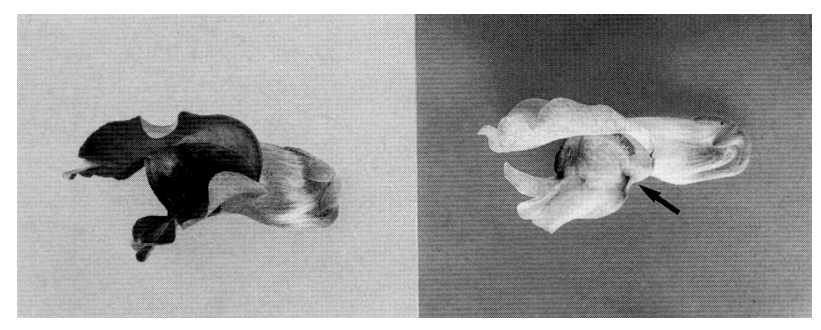

Figure 3. Notched phenotype produced in some of the $F_{1} c y c$ heterozygotes. (Left) Homozygous wild type with typical "closed" corolla; (right) a notch (arrow) between the upper and lower lobes, resulting in the partially open corolla as seen, e.g., in the $F_{1}$ of $c y c-608 \times c y c^{\text {hemi }}$. The difference in the color is due to the presence of the Eluta gene in the $c y c^{\text {hemi }}$ parent. third whorl there were five united carpels, the top of which formed a flattened hollow ring of pollen-receptive stigmatic tissue. The number and position of the carpel primordia were identical to those of the wild-type stamens, indicating a homeotic conversion of stamen to carpel in the mutant. In the most extreme mutant phenotypes, the fourth whorl did not usually develop organs, but in less extreme cases it developed as wildtype carpels (Fig. 4a-c). Therefore, the first three whorls of the flower had been altered to give sepal, sepal, carpel, instead of the normal sepal, petal, stamen. Mutations giving a similar phenotype have been described previously at three different loci, def, globosa (glo), and viridiflora (vir) (Stubbe 1966). Crosses with plants carrying def or glo alleles showed that the mutation was a recessive allele of the def locus, subsequently referred to as def-621 (Table 2).

The def-621 allele was somatically very unstable. Clonal islands of pigmented tissue, sometimes comprising only four cells, were observed on the second whorl of sepals. Petal epidermal cells have a shape distinct from those of the sepal. Scanning electron micrographs showed that the clonal patches were composed of petal-like cells, with a sharp boundary separating them from the surrounding sepal cells (Fig. 5). To determine whether the subepidermal layers were also altered, small clonal patches were examined in transverse section. The cell layers beneath the epidermal patches were green, resembling mesophyll cells of the sepal rather than the unpigmented subepidermal petal cells. Occasionally, entire wild-type flowers were produced on the mutant, presumably caused by early somatic reversion events, but no viable seed was obtained. In addition, small flowers containing much reduced stamens were sometimes seen and resembled the phenotype of the defnicotinoides $\left(d e f^{\text {nic }}\right)$ allele described previously (Hertwig 1926).

sepaloidea-619 and sepaloidea-620 A mutation was obtained which, in its most extreme form, gave a sepal, sepal, carpel phenotype similar to def and glo mutants. The phenotype was, however, very variable with a tendency to produce large areas of petaloid tissue, usually edged with sepal-like areas in the second whorl (Fig. $4 d-f)$. The stylar tissue of the third whorl was not always united and, in some cases, was petaloid. Crossing with plants carrying def or glo alleles or the wild-type progenitor gave only wild-type $F_{1}$ progeny (Table 2 ), indicating that the mutation was a recessive allele of a new locus. Therefore, this mutation will subsequently be referred to as sepaloidea-620 (sep-620). This may correspond to the vir locus, a mutant that is unfortunately no longer available for testing (von Kuckuck and Schick 1930; Bergfeld 1956).

An independent mutation was obtained that gave flowers with a similar phenotype to sep-620 but less extreme. Some flowers had separate small green-edged petals in the second whorl and vestigial anthers in the third whorl clustered tightly around a gynoecium with a short style. The second whorl of other flowers contained large upper petals streaked with green tissue and small 


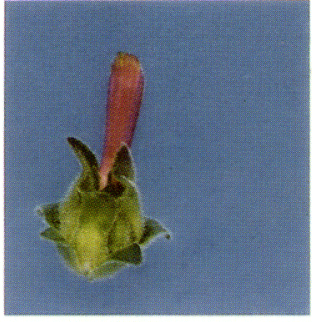

a

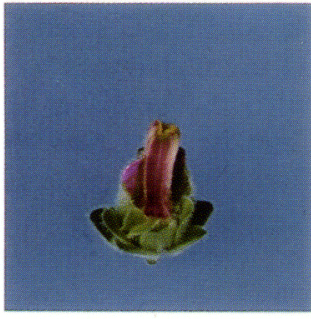

d

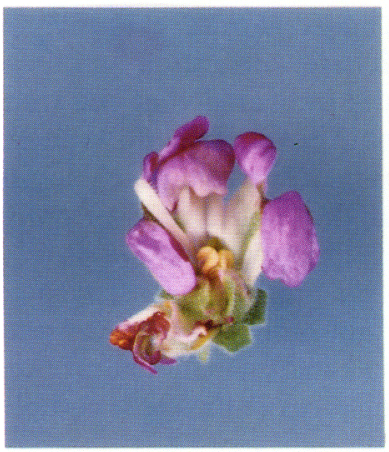

g

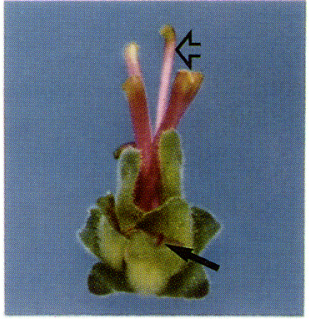

b

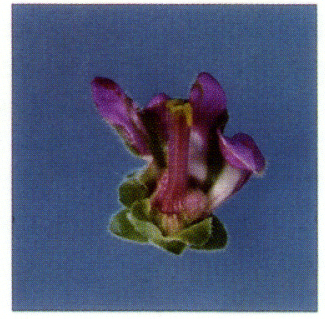

e

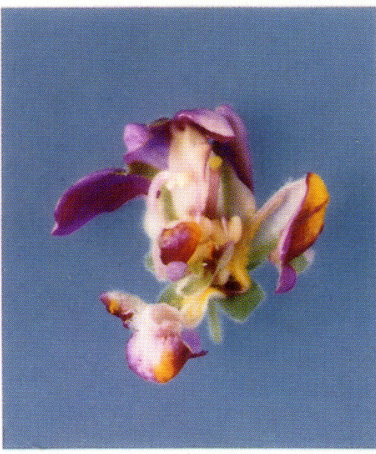

h

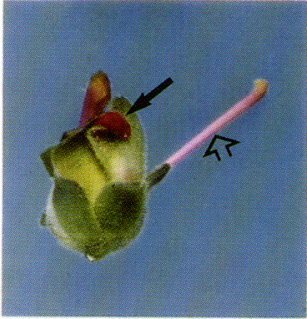

C

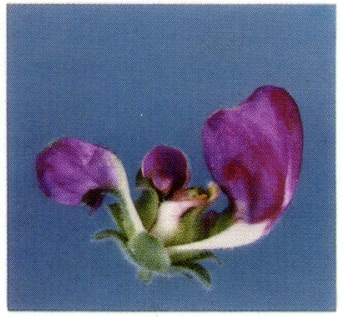

f

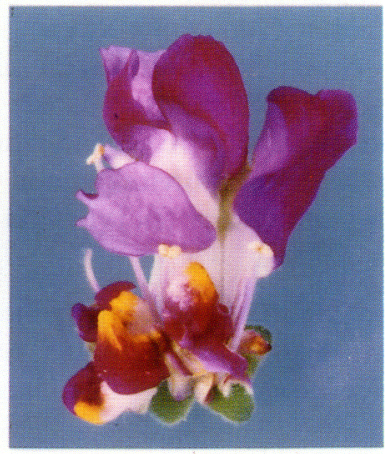

i

Figure 4. Diversity of flowers produced by def-621, sep-620, and sep-619, showing a series of progressively less severe phenotypes. $(a-c)$ The def-621 flowers showing the second whorl of sepals with clonal patches of red petal tissue (solid arrows) and the united five carpels of the third whorl. Open arrows on flowers $b$ and $c$ show the central carpels of the fourth whorl. $(d-f)$ sep-620 flowers with the extreme form $(d)$ being similar to that of def-621. $(g-i)$ Flowers from the sep-619 mutation, with the least phenotype on the right (i).

separate lower petals; the other whorls of the flower appeared normal (Fig. $4 \mathrm{~g}-\mathrm{i}$ ). Two capsules of viable seed were obtained, and all progeny had a mutant phenotype. Crossing to plants carrying def or glo gave wild-type progeny, whereas mutant progeny resulted with sep, indicating that the mutation was at the sep locus. This mutation will be referred to as sepaloidea-619 (sep-619; Table 2). The various flowers produced by the sep- 620 and sep-619 mutations can be arranged in a series of progressively less severe phenotypes (Fig. 4).

ovulata-627 Unlike other mutations described so far, this mutant was detected in the $M_{1}$ generation, indicating that it was dominant or semidominant to wild type. Several different $M_{1}$ plants, all derived from the same parent, showed a range of related phenotypes. The most severe of these gave five carpeloid members in the first whorl; the uppermost was separate and did not contain ovules, whereas the lower four formed two structures, each comprising two ovule-bearing loculi terminating in separate style-like structures. The second whorl contained separate strap-like petals, the lower three occasionally exhibiting anther-like structures; the third and fourth whorls were normal (Fig. 6). One of these severe mutants was self-pollinated and gave an $\mathbf{M}_{2}$ of 3 wild type, 12 parental phenotypes, and 6 mutants with an extreme phenotype. The first whorl of this extreme phenotype comprised five carpels, the uppermost lacking ovules and the lower four being united to give an ovary with four ovule-bearing loculi terminating in a united band of stylar tissue. The second whorl comprised three lower stamens, whereas the upper two 
Carpenter and Coen

Table 2. Results of allelism tests for def-621, sep-620, and sep-619

\begin{tabular}{lcccc}
\hline & Def/defgli & defchlor & Glo/glo & sep-619 \\
\hline def-621 & wild type and mutant & mutant & wild type & wild type \\
sep-620 & wild type & - & wild type & wild type \\
sep-619 & - & - & wild type & mutant \\
Def/defgli & - & - & - & mutant \\
\hline
\end{tabular}

Phenotypes observed in $\mathrm{F}_{1}$ progeny when known def and glo mutations were intercrossed with def-621, sep-620, and sep-619. Mutant progeny indicate allelism between parental plants. Female parent is indicated in the left column and male parent along the top row.

members remained as small vestigial or aborted structures; the third and fourth whorls were wild type (Fig. $6 \mathrm{~A}, \mathrm{~B})$. The new phenotype may be summarized as carpel, stamen, stamen, carpel. The near $1: 2: 1$ segregation of the $M_{2}$ progeny suggested that the mutation, called ovulata-627 (ovu-627), was semidominant, the parental phenotype being that of the heterozygote and the extreme phenotype being the ovu homozygote. This was confirmed because progeny from the $\mathrm{M}_{2}$ heterozygotes segregated $1: 2: 1$, the $M_{2}$ wild types bred true, and all progeny from backcrosses of the $M_{2}$ ovu homozygotes to wild type had the heterozygous phenotype.

Two of the less severe $M_{1}$ plants were also studied. One of these had elongated pointed sepals in the first whorl and large split petals in the second whorl. Somatically, the other was highly unstable and sometimes showed the full range of ovu phenotypes on a single raceme.

pleniflora-624, pleniflora-625, and pleniflora-626 Several independent mutations were isolated, which gave a very similar phenotype. The first and second whorls

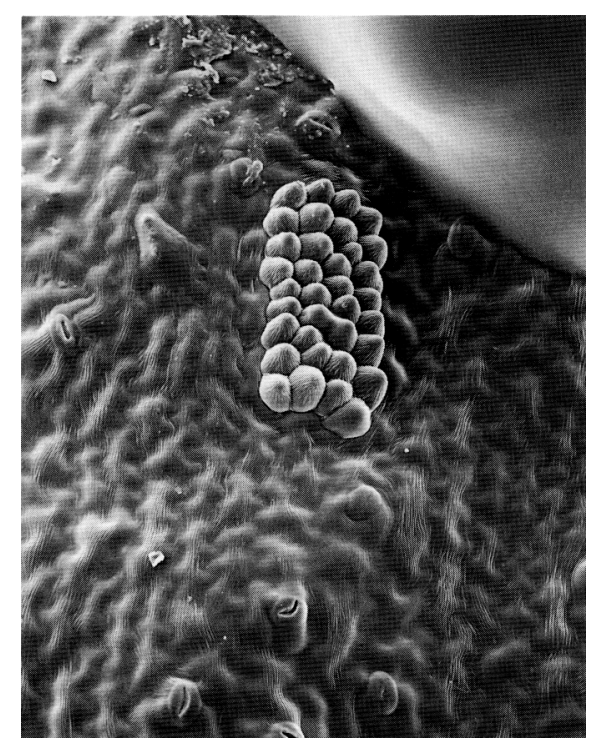

Figure 5. Scanning electron micrograph of part of the second whorl of sepals in the def-621 mutant, showing an island of 35 petal cells with a sharp boundary separating them from the surrounding sepal tissue. This indicates somatic excision of a transposon from the def gene leading to restoration of gene function. were similar to wild type, whereas the third whorl contained petaloid members that were united for most of their length with the petals of the second whorl. The fourth whorl consisted of two members with variable structures, which showed sepaloid, carpeloid, and petaloid features. These structures were in the same relative position as the wild-type carpels. Within the fourth whorl were up to five extra whorls of petaloid members.

Two of the mutations were unstable somatically and gave occasional wild-type flowers on otherwise mutant spikes. Seeds from these gave both wild-type and mutant progeny. The wild-type progeny were self-pollinated and, in each case, segregated for mutants and wild types. These results indicated that the mutations were recessive and could revert to wild type in both somatic and germinal tissue. The two unstable mutations have been called pleniflora-624 and plenifora-625 (pleni-624 and pleni-625, respectively) and a third phenotype, which has not so far produced seed, was called plenifora- 626 (pleni-626) and propagated by vegetative cuttings. It has not yet been established whether these three mutations belong to the same or different complementation groups.

floricaula-613 In this mutant, the switch from vegetative growth to that of the reproductive spike was as normal. In the axil of each bract, however, a secondary shoot formed instead of a pedicel and flower. This shoot, in turn, produced bracts within the axils of which further bract-bearing shoots were produced. This process could continue indefinitely to form an indeterminate shoot that had lost its ability to flower (Fig. 7).

It was necessary to propagate this mutation vegetatively, and a number of cuttings were grown at $15^{\circ} \mathrm{C}$. One of these produced occasional flowers that were either self-pollinated or backcrossed to the wild-type progenitor. The progeny from the backcross were all wildtype, and when self-pollinated, gave wild-type and mutant progeny in approximately a $3: 1$ ratio $(39: 15)$. This indicated that the mutation was recessive, and it was called floricaula-613 (flo-613). From the occasional flowers produced by these cuttings, five capsules of viable selfed seed were obtained and the progeny from four of these capsules were all mutant. However, one of the capsules gave progeny that segregated to give 4 mutant and 18 wild-type plants, indicating that germinal reversion to the wild-type allele had occurred. The progeny from the wild types showed that some were heterozygous and others were homozygous for the wild-type allele. 

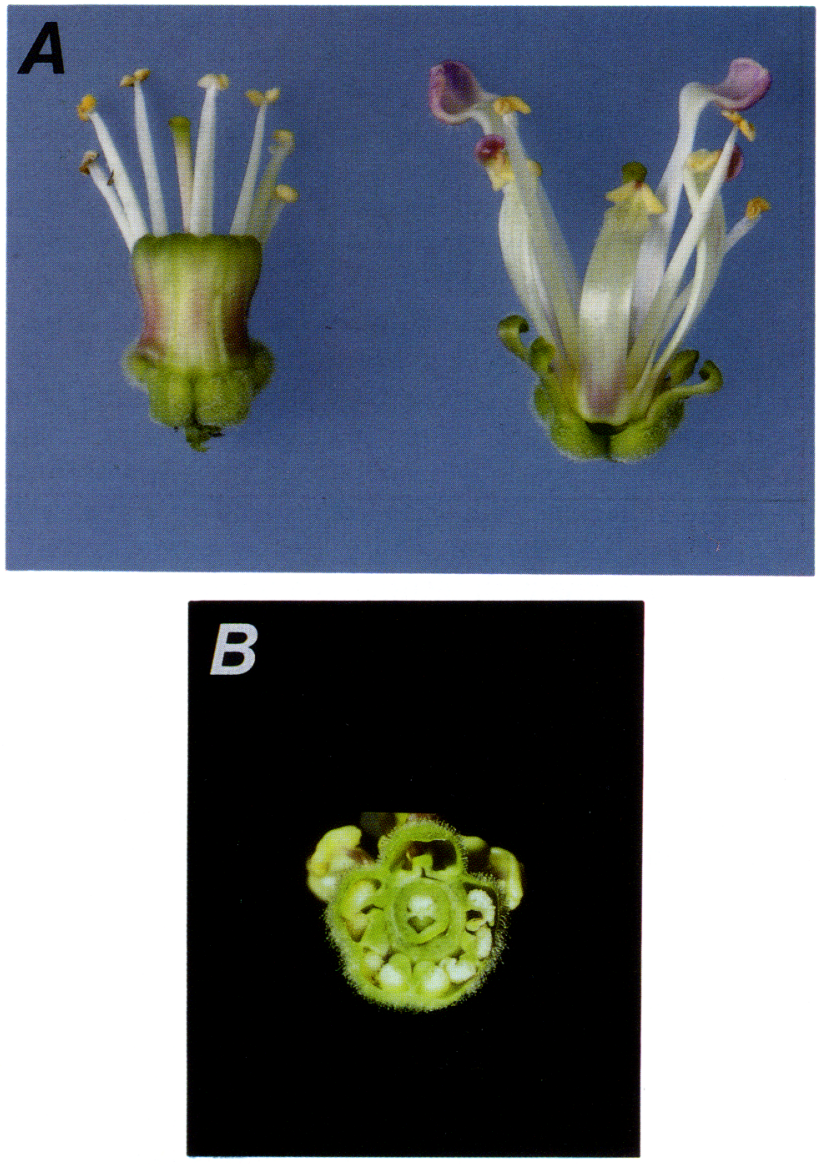

Figure 6. (A) Flowers of the mutant ovu-627. (Left) Homozygote showing the united carpels growing in place of sepals and three stamens in place of the three lower petals, giving a total of seven stamens. (Right) Heterozygous form of ovu-627, giving a mutant phenotype that is less extreme than that of the homozygote. $(B)$ Transverse section through a homozygous ovu-627 showing that ovules are arranged within the outer lower four carpels, whereas the upper appears empty. Ovules are produced within the normal bilocular central ovary.

\section{Discussion}

Ten floral homeotic mutations were obtained, which can be divided into three classes. The first class affects the identity of members within the same whorl and includes the cyc alleles that confer varying degrees of radial symmetry to the flower. Two independent mutations giving this phenotype were obtained, and genetic analysis of these allowed two groups of $c y c$ alleles to be defined. Extreme alleles of one group confer a peloric phenotype in which all members of whorls two and three resemble the middle lowest member of the corresponding whorls in the wild-type flower. The second group also gives flowers that are more symmetrical than wild type but retain a degree of zygomorphy. Crosses between plants carrying alleles from the different groups give $F_{1} s$ with an almost wild-type phenotype but with two small notches on the lower flower lip, showing that alleles from the two groups complement each other par- tially. This suggests that cyc may be a complex locus composed of two interacting functional components. Alternatively, it is possible that there are two distinct cyc genes that are linked on the chromosome and whose products interact.

The second class of homeotic mutations affects the identity and sometimes, in addition, the number of whorls. Mutations at two loci, def and sep were obtained which, in the most extreme form, resulted in sepals growing in place of petals and carpels instead of stamens to give the phenotype sepal, sepal, carpel. The development of the fourth whorl did not usually occur in the extreme phenotype but comprised two united carpels in less severe forms. A third unlinked locus, glo, has also been described, which gives this phenotype (von Kuckuck and Schick 1930). The phenotype carpel, stamen, stamen, carpel is conferred by the most extreme allele obtained at the ovu locus. Unlike the other homeotic mutations obtained, ovu alleles are semidominant to wild type.

These two homeotic phenotypes suggest a simple model for the determination of whorl identity involving the combinatorial interaction of two functions, $a$ and $b$. The $a$ function is expressed in the outer two whorls of wild type, whereas the $b$ function is expressed in the middle two whorls so that expression of $a$ alone gives sepals, of $a$ and $b$ gives petals, of $b$ alone gives stamens, and of neither gives carpels (Fig. 8). The ovu phenotype is consistent with the absence of the function $a$. The semidominance of ovu alleles suggests that they may be preventing the expression or action of the $a$ function

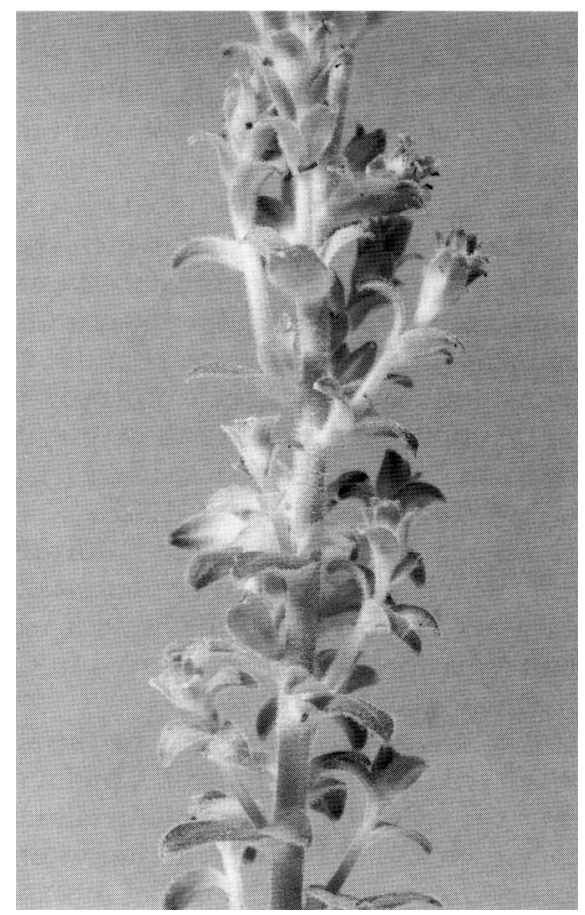

Figure 7. The flo-613 mutation showing a raceme with a shoot of indeterminate growth, instead of a flower, being produced within the axil of each bract. 


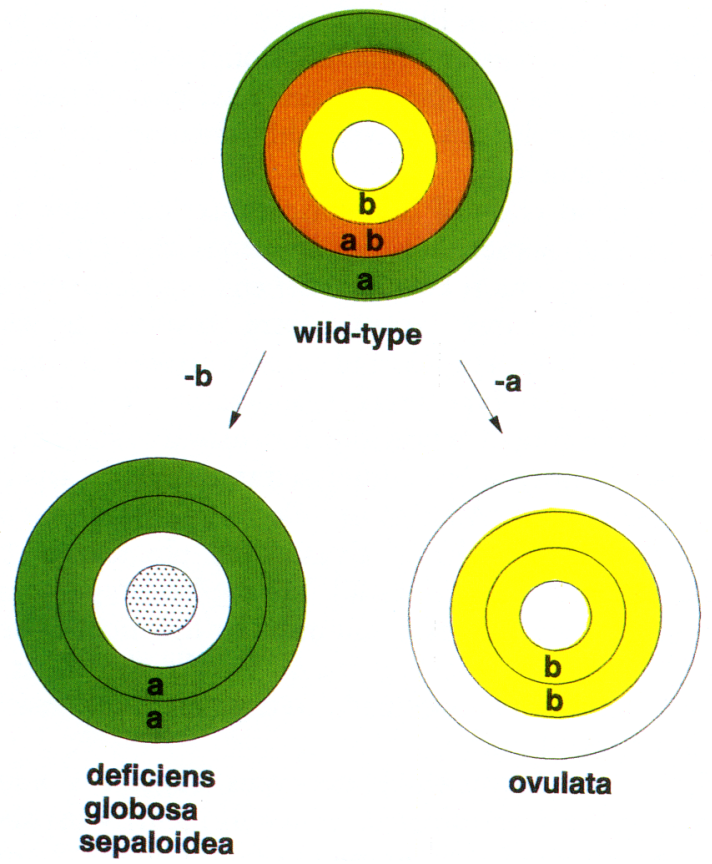

Figure 8. Model for the determination of whorl identity. In the wild type, the first whorl of sepals (green) expresses the $a$ function; the second whorl of petals (red) expresses $a$ and $b$; the third whorl of stamens (yellow) express $b$ alone; the fourth whorl of carpels (white) expresses neither function. Mutant phenotypes are indicated below. The def, glo, and sep mutants are explained by loss of the $b$ function. The stippled area indicates that the fourth whorl does not usually develop in the extreme phenotypes. In less extreme cases it gives carpels. The ovu phenotype is explained by absence of the $a$ function.

rather than causing a loss of function. The def, glo, and sep phenotypes would result from loss of the $b$ function. The absence of the fourth whorl in some of the def mutants suggests that the $b$ function may also affect the determination of whorl number. Mutant phenotypes have been described in Arabidopsis, which show many similarities to those of Antirrhinum (def, sep, and glo are similar to pistillata and apetala-3; ovu is similar to apetala-2; Komaki et al. 1988; Bowman et al. 1989). For Arabidopsis, models have also been proposed involving concentric functions, and some of these may be analogous to the $a$ and $b$ functions proposed here (Haughn and Sommerville 1988; Bowman et al. 1989). The remarkable similarities between mutants in Antirrhinum and Arabidopsis, which belong to two taxonomically distant plant subclasses, suggest that the genetic control of whorl identity has been highly conserved in the evolution of dicotyledonous plants.

The pleni mutants give flowers with the first three whorls of the type sepal, petal, petal. The fourth whorl comprises two variable carpeloid/petaloid/sepaloid structures and within these a proliferation of petaloid whorls occurs. According to the model presented here, the wild-type pleni product might be required for a third function (c), which inhibits expression of the $a$ function in the third whorl, so that the mutant expresses both $a$ and $b$ to give petal. In addition, it would act in the third or fourth whorls to delimit whorl number such that the mutant reinitiates both the production of whorls and the expression of the $a$ and $b$ functions, giving them a petaloid character. In this respect pleni mutants may be similar to heterochronic mutants in Caenorhabditis elegans, which repeat early lineages at later stages of development (Ambros and Horvitz 1984). The pleni phenotype is similar to other mutations described in Antirrhinum (Bergfeld 1956) and also to the agamous phenotype in Arabidopsis, although, in this case, sepals grow in the fourth whorl (Bowman et al. 1989). It is important to note that the spatial pattern of the expression of the $a$, $b$, and $c$ functions may also correspond to a temporal sequence as the different whorls 1-4 arise sequentially.

Genes affecting both identity and number of homologous parts have also been described in Drosophila (see Ingham 1988). All of the Drosophila mutants give fewer rather than more homologous members compared to wild type. This may reflect a fundamental difference in the mechanism by which the repetition of parts occurs in these two systems. In Drosophila, segmentation proceeds from an undivided structure, the egg, to a subdivided one, so that mutants failing to subdivide correctly give fewer segments. In plants, whorl primordia are produced by sequential growth rather than by subdivision, giving the potential for indeterminant growth. The flower has been considered as homologous to a shoot with an imposed determinate growth pattern so that mutations in genes required for determinancy might be expected to give a proliferation of whorls (von Goethe 1790; Worsdell 1907; Arber 1937).

Thus far, the actions of the whorl identity genes have been considered separately from the first class of genes that affect the identity of members within a whorl. However, it is likely that these two gene classes also interact in a combinatorial way. For example, only three stamens develop in the second whorl of ovu mutants because the upper two members are vestigial or aborted. Therefore, these two members adopt a fate similar to that of the uppermost member of the wild-type stamen whorl (Fig. 1). Abortion of this member depends on the action of the wild-type cyc product, because in extreme cyc mutants all stamens develop fully and resemble the lower stamens of wild type. This suggests that the $\mathrm{Cyc}^{+}$ product interacts with primordia in a similar way, irrespective of the whorl in which they occur and that the fate of a primoridum therefore depends on an interaction between the functions determining whorl identity and the functions determining the differences between upper and lower members within a whorl $(c y c)$. In wild-type, the fate of a primordium may therefore be determined by a polar coordinate system (Fig. 9). Expression of the whorl identity functions varies along the radius $(r)$ of the flower. The $c y c$ function varies along the vertical $(y)$ axis of the flower, with its effect generally increasing from the lower to the upper parts of the axis. This results in bilateral symmetry, because for half of the flower, every member has a unique specification, identical with its mirror image in the other half (Fig. 9). 


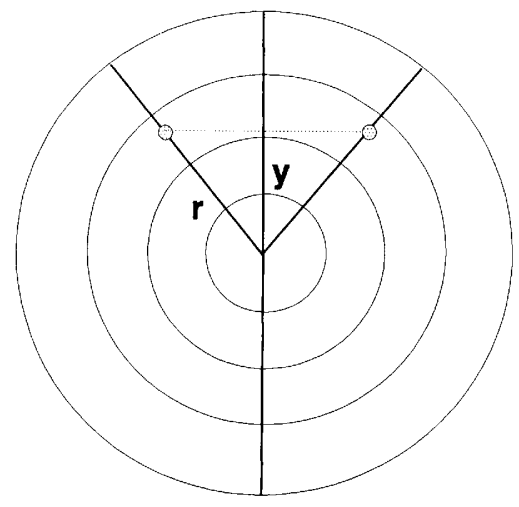

Figure 9. Polar coordinate system for specifying primordium fate. The four whorls are shown as concentric rings. Expression of the whorl identity functions varies along the radius $(\mathbf{r})$ of the flower. The cyc function varies along the vertical $(y)$ axis of the flower, with its effect generally increasing from the lower to the upper parts of the axis. Two members with the same combination of functions and, hence, the same developmental fate, are shown joined by a dotted horizontal line. Mutations eliminating the whorl identity functions result in some members from different whorls having similar specifications so that they adopt similar developmental fates. Mutations that abolish cyc function remove differential expression along the y axis such that all members of a whorl adopt a fate similar to that of the lower member of the wild-type whorl.

The third class of mutants gives indeterminant shoots in place of flowers in the axils of bracts. In the flo mutant, these lateral shoots bear bracts that can produce further lateral shoots in their axils, thus giving an indeterminant growth pattern. The wild-type flo product is therefore required for switching indeterminate shoot meristems to floral meristems and presumably activates the expression of the other classes of floral homeotic genes, either directly or indirectly. The phenotype is similar to other mutations in Antirrhinum (Chittenden 1928; von Kuckuck and Schick 1930; Bergfeld 1960) and to the anantha mutant of tomato, which also results in indeterminate branching of the inflorescence without production of flowers (Helm 1951; Paddock and Alexander 1952).

\section{Cell-autonomy of mutants}

Many of the homeotic mutants show instability in somatic or germinal tissue, suggesting that they were transposon induced. In some cases, the instability may be used to investigate the cell-autonomy of the genes affected. The def-621 allele shows clonal patches of petal tissue on the epidermis of the second whorl of sepals. These patches are separated by sharp boundaries both from the surrounding sepal epidermal tissue and from the underlying mesophyll tissue and can be explained by somatic excision of a transposon from the def locus restoring gene function. This suggests that the product of the wild-type def gene is not diffusible between cells and acts cell autonomously, at least in the epidermis of the second whorl. The observation of some very small patches indicates that the def product is active throughout development of the petal, from the early stages when petal and sepal primordia become distinct to the final cell divisions of the petal. This agrees with studies on the transcription of def, which show that gene expression is maintained from early to late stages of flower development (Sommer et al. 1990). The consequences of def expression may be different at each developmental stage, so that at early stages it may affect patterns of cell division and expansion and, hence, the form of the petal; at later stages it may determine whether cells have the petal or sepal characteristics typical of fully developed flowers. This may explain why both the form and the cell types of the second whorl organs appear to be intermediate between petal and sepal in some of the less extreme def alleles such as defnic and defchlorantha (Hertwig 1926).

As the clonal patches of def-621 occur only in the second and not the first whorl of sepals, there must be other genes that act specifically in the second whorl throughout its development, which are necessary either for def expression or for the action of the def product. Two such genes may be glo and sep, as mutations of these give a similar phenotype of the def mutant. Interestingly, the apetala-3 mutation of Arabidopsis, which gives a similar phenotype to def, glo, and sep, is also thought to act up to a late stage of organ development based on temperature-shift experiments (Bowman et al. 1989).

A further feature revealed by the small clonal patches is that expression of def in whorl 2 early in development is not necessary for its later expression. This is because def can be expressed correctly late in development without any previous history of def activity in the organ. This rules out models in which def is switched on by a transient early signal and then def maintains independently its own expression by autoregulation. In this respect, small clonal wild-type patches in mutant tissue are more informative than the usual mosaic analysis of recessive mutants, carried out in other organisms such as Drosophila and maize, which invariably involve mutant patches in wild-type tissue and thus do not give any information about self-maintenance of gene expression.

Somatic instability was also observed for the flo mutant, because occasional flowers were seen in otherwise mutant inflorescences. In four cases, seed derived from these flowers gave only mutant progeny, whereas, in one case, the progeny segregated wild type to mutant in a ratio of $3: 1$. The observed case of germinal transmission of the revertant phenotype suggests that the parental flowers were the results of somatic excision of a transposon from flo restoring gene function. The failure of germinal transmission in most cases shows that functional gametes can be produced from homozygous mutant tissue and suggests that flo does not act cell autonomously. Another explanation is that some of the flowers observed are not the result of somatic transposon excision but are due to leakiness of the flo mutation.

The germinal and somatic instability observed for 
many of the homeotic mutations suggests that they were caused by transposon insertions. In addition, molecular analysis of leaf and flower pigmentation mutants obtained from the same transposon mutagenesis experiment has shown that in most cases they were caused by transposon insertion, allowing new genes to be isolated and new transposons to be trapped (D. Luo, E. Coen, S. Doyle, and R. Carpenter, unpubl.). It should now be possible to determine which transposons are responsible for the homeotic mutations, allowing the isolation and molecular analysis of the genes involved.

\section{Materials and methods}

\section{Antirrhinum stocks}

JI.98 nivea ${ }^{\text {recurrens }}-98\left(\right.$ niv $\left.^{\text {rec }}-98\right)$ and JI.75 (TR-75) were bred at the John Innes Institute and are described by Harrison and Carpenter (1979) and Carpenter et al. (1987). The lines JI.522 and JI.523 were wild-type revertants of JI.98 and had been inbred as homozygous stocks for at least three generations. Families $\mathrm{T} 144, \mathrm{~T} 145$, and T147 were heterozygous revertants of a highly unstable line carrying niv rec-98. The cyc-25 mutation was obtained from L.K. Crowe at Oxford prior to 1963 and has subsequently been maintained at our Institute. The stock JI.26 globosa allele arose spontaneously at John Innes in 1963 and is maintained as a heterozygous stock. All alleles carry the same number as the lines in which they are maintained. We are grateful to C. Lehmann for supplying the series of $c y c$ and deficiens (def) mutations described by Stubbe (1966).

The conditions under which the plants were grown were the same as those described in Carpenter et al. (1987). Scanning electron micrographs were prepared as described by Williams and Green (1988).

\section{Transposon mutagenesis strategy}

In each case, 10 or 15 plants of lines that carry highly active transposons, (JI.75, JI.98, JI.522, and JI.523 and families of T144, $\mathrm{T} 145$, and $\mathrm{T} 147)$ were grown at a constant $15^{\circ} \mathrm{C}$, the temperature at which the highest frequency of transposition occurs (Harrison and Fincham 1964; Harrison and Carpenter 1973). These plants were self-pollinated, and seed capsules were collected separately. Seed from these plants gave rise to families of either 15 or 30 plants from each capsule, with a total of 13,000 $M_{1}$ plants grown in the greenhouse. As most mutations were likely to be recessive, these $M_{1}$ plants were also self-pollinated. To economize on labor, two capsules from each of the 15 or 30 plants within a family were pooled and mixed thoroughly to give a family bag of seed. In addition, two capsules from each plant derived from a particular line were collected in one bag and mixed thoroughly to form a line bag. For the $\mathrm{M}_{2}$ generation, seed from each of the family bags was sown to give either 48 or 96 plants, depending on whether the $M_{1}$ family comprised 15 or 30 plants, to give a total $M_{2}$ generation of 40,000 plants grown in the field.

The main advantage of using family bags was that any mutation isolated could be traced back to its family, and further plants carrying the same mutation could be isolated. The line bags allowed the production of a large pool of mutagenized seed, which can be screened easily for diverse mutations, providing a long-term genetic resource.

\section{Acknowledgments}

We thank David Hopwood, Andrew Hudson, Justin Goodrich, and José Romero for critical reading of the manuscript; Michel Goldschmidt-Clermont for helpful comments; and Kathryn Blewett, Karen Ingle, and Audrey Cooper for assistance during their summer vacations. We are grateful to Paul Green and Ruth Magrath for producing the scanning electron micrograph for Figure 5. We give special thanks to Peter Scott and Andrew Davies for their photography, to the Glasshouse and Field Services Department for growing the acres of plants, and to Anne Williams for typing the manuscript. We acknowledge a generous grant from the Gatsby Foundation, which enabled us to carry out the transposon mutagenesis experiment.

The publication costs of this article were defrayed in part by payment of page charges. This article must therefore be hereby marked "advertisement" in accordance with 18 USC section 1734 solely to indicate this fact.

\section{References}

Almeida, J., R. Carpenter, T.P. Robbins, C. Martin, and E.S. Coen. 1989. Genetic interactions underlying flower color patterns in Antirrhinum majus. Genes Dev. 3: 1758-1767.

Ambros, V.R. and H.R. Horvitz. 1984. Heterochronic mutants of the nematode Caenorhabditis elegans. Science 226: 409416.

Arber, A. 1937. The interpretation of the flower: A study of some aspects of morphological thought. Biol. Rev. 12: 157184.

Awasthi, D.K., V. Kumar, and Y.S. Murty. 1984. Flower development in Antirrhinum majus (Scrophulariaceae) with a comment upon corolla tube formation. Bot. Mag. Tokyo 97: 13-22.

Bateson, W. 1894. Materials for the study of variation treated with the especial regard to discontinuity in the origin of species, pp. 84-85. MacMillan, New York and London.

Bergfeld, R. 1956. Entwicklungsgeschichtliche untersuchungen an einigen Blütenformmutanten der Sippe 50 von Antirrhinum majus. Z. Indukt. Abstamm. Vererbungsl. 87: 784789.

. 1960. Zür Frage nach der Blütenbildung bei Antirrhinum majus mut. sterilis. Pyropfversche und Wuchssloffanalysen. Z. Bot. 48: 170-181.

Bonas, U., H. Sommer, B.J. Harrison, and H. Saedler. 1984. The transposable element Taml of Antirrhinum majus is $17 \mathrm{~kb}$ long. Mol. Gen. Genet. 194: 138-143.

Bowman, J.L., D.R. Smyth, and E.M. Meyerowitz. 1989. Genes directing flower development in Arabidopsis. Plant Cell 1: $37-52$.

Carpenter, R., C.R. Martin, and E.S. Coen. 1987. Comparison of genetic behaviour of the transposable element Tam3 at two unlinked pigment loci in Antirrhinum majus. Mol. Gen. Genet. 207: 82-89.

Chittenden, R.J. 1928. Note on an abnormal Antirrhinum. J. Genet. 19: 281-283.

Coen, E.S., R. Carpenter, and C. Martin. 1986. Transposable elements generate novel spatial patterns of gene expression in Antirrhinum majus. Cell 47: 285-296.

Darwin, C. 1868. The variation of animals and plants under domestication, vol. 2, pp. 59-60. Murray, London.

Harrison, B.J. and R. Carpenter. 1973. A comparison of the instabilities at the nivea and pallida loci in Antirrhinum majus. Heredity 31: 309-323.

. 1979. Resurgence of genetic instability in Antirrhinum majus. Mutat. Res. 63: 47-69.

Harrison, B.J. and J.R.S. Fincham. 1964. Instability at the Pal locus in Antirrhinum majus. 1. Effects of environment on frequencies of somatic and germinal mutation. Heredity 
19: $237-258$.

Haughn, G.W. and C.R. Somerville. 1988. Genetic control of morphogenesis in Arabidopsis. Dev. Genet. 9: 73-89.

Helm, J. 1951. Vergleichende Betrachtungen über die Entwicklung der Enfloreszenz bei Lycopersicum esculentum Mill. und bei einer Röntgenmutante. Zeuchter 21: 89-95.

Hertwig, P. 1926. Ein neuer Fall von multiplen Allelomorphisms bei Antirrhinum. Z. Indukt. Abstamm. Vererbungsl. 41: 42-47.

Ingham. 1988. The molecular genetics of embryonic pattern formation in Drosophila. Nature 335: 25-36.

Komaki, M.K., K. Okada, E. Nishino, and Y. Shimura. 1988. Isolation and characterisation of novel mutants of Arabidopsis thaliana defective in flower development. Development 104: 195-203.

Krebbers, E., R. Hehl, R. Piotrowiak, W. Lönnig, H. Sommer, and H. Saedler. 1987. Molecular analysis of paramutant plants of Antirrhinum majus and the involvement of transposable elements. Mol. Gen. Genet. 209: 499-507.

Martin, C., R. Carpenter, H. Sommer, H. Saedler, and E.S. Coen. 1985. Molecular analysis of instability in flower pigmentation of Antirrhinum majus, following isolation of the pallida locus by transposon tagging. EMBO J. 4: 1625-1630.

Masters, M.T. 1869. Vegetable teratology: An account of the principle deviations from usual construction of plants. Royal Society, London.

Meyer, V. 1966. Flower abnormalities. Bot. Rev. 32: 165-195.

Meyerowitz, E.M., D.R. Smyth, and J.L. Bowman. 1989. Abnormal flowers and pattern formation in floral development. Development 106: 209-217.

Paddock, E.F. and L.J. Alexander. 1952. Cauliflower, a new recessive mutation in tomato. Ohio J. Sci. 52: 327-334.

Shepherd, N.S. 1987. Transposable elements and gene tagging. In Plant molecular biology: A practical approach (ed. C.H. Shaw). pp. 187-281. IRL Press, London.

Sommer, H. and H. Saedler. 1986. Structure of the chalcone synthase gene of Antirrhinum majus. Mol. Gen. Genet. 202: 300-305.

Sommer, H., R. Carpenter, B.J. Harrison, and H. Saedler. 1985. The transposable element Tam3 of Antirrhinum majus generates a novel type of sequence alterations upon excision. Mol. Gen. Genet. 199: 225-231.

Sommer, H., U. Bonas, and H. Saedler. 1988. Transposon-induced alterations in the promoter region affect transcription of the chalcone synthase gene of Antirrhinum majus. Mol. Gen. Genet. 211: 49-55.

Sommer, H., J.-P. Beltran, P. Huijner, H. Pape, W.-E. Lönnig, H. Saedler, and Z. Schwarz-Sommer. 1990. Deficiens, a homeotic gene involved in the control of flower morphogenesis in Antirrhinum majus: The protein shows homology to transcription factors. $E M B O$ J. 9: 605-613.

Stubbe, H. 1966. Genetik und Zytologie von Antirrhinum L. sect Antirrhinum. Veb Gustav Fischer Verlag, Jena.

Upadhyaya, K., H. Sommer, E. Krebbers, and H. Saedler. 1985. The paramutagenic line niv-44 has a 5 -kb insert, Tam2, in the chalcone synthase gene of Antirrhinum majus. Mol. Gen. Genet. 199: 201-207.

von Goethe, J. 1790. Versuch die Metamorphose der Pflanzen zu erkläen. transl. Arber A. 1946 Goethe's Botany Chron. Bot. 10: 63-126.

von Kuckuck, H. 1936. Über vier neue Serien multipler Allele bei Antirrhinum majus. Z. Indukt. Abstamm. Vererbungsl. 71: 429-440.

von Kuckuck, H. and R. Schick. 1930. Die Erbfaktoren bei Antirrhinum majus und ihre Bezeichung. Z. Indukt. $A b$ stamm. Vererbungsl. 56: 51-83.
Wienand, U. and H. Saedler. 1987. Plant transposable elements: Unique structures for gene cloning. Plant gene research. In Plant DNA infectious agents (ed. T.H. Hohn and J. Schell), pp. 205-227.

Williams, M.H. and P.B. Green. 1988. Sequential scanning electron microscopy of a growing plant meristem. Protoplasma 147: $77-79$.

Worsdell, W.C. 1907. The origin of the flower. Sci. Prog. 6: 1-8. 1915. The principles of plant teratology, vol. I. Ray Society, London.

1916. The principles of plant teratology, vol. II. Ray Society, London. 


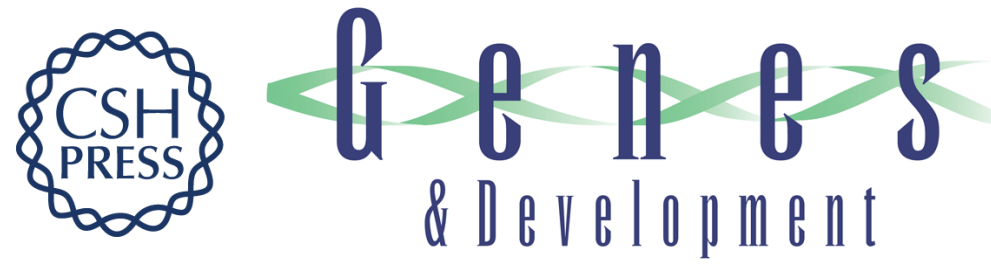

\section{Floral homeotic mutations produced by transposon-mutagenesis in Antirrhinum majus.}

$\mathrm{R}$ Carpenter and E S Coen

Genes Dev. 1990, 4:

Access the most recent version at doi:10.1101/gad.4.9.1483

References This article cites 34 articles, 5 of which can be accessed free at:

http://genesdev.cshlp.org/content/4/9/1483.full.html\#ref-list-1

License

Email Alerting

Service

Receive free email alerts when new articles cite this article - sign up in the box at the top right corner of the article or click here.

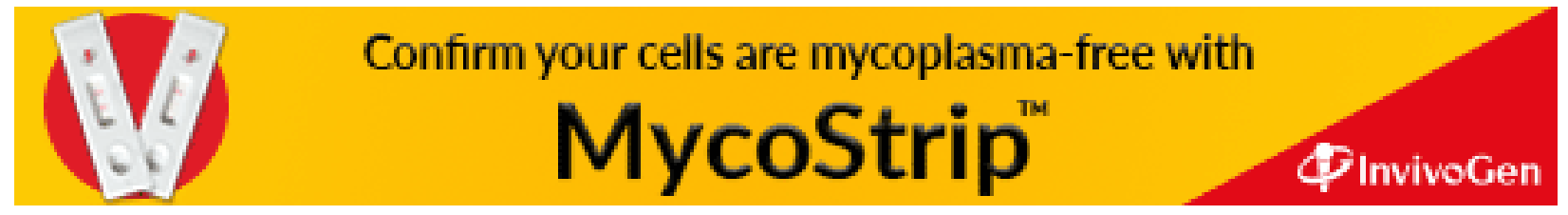

